\title{
The effect of fibre amount, energy level and viscosity of beverages containing oat fibre supplement on perceived satiety
}

\author{
Marika Lyly',2*, Nora Ohls',3, Liisa Lähteenmäkil,4, \\ Marjatta Salmenkallio-Marttila', Kirsi-Helena Liukkonen ${ }^{1,2}$, \\ Leila Karhunen ${ }^{5}$ and Kaisa Poutanen ${ }^{1,5}$
}

'VTT Technical Research Centre of Finland, VTT, Finland; ²Finnish Food Safety Authority Evira, Helsinki, Finland;

${ }^{3}$ ActPro Oy, Helsinki, Finland; ${ }^{4}$ MAPP Aarhus School of Business, Aarhus University, Aarhus V, Denmark; ${ }^{5}$ Department of Clinical Nutrition, Food and Health Research Centre, Institute of Public Health and Clinical Nutrition, University of Eastern Finland, Kuopio, Finland

Abstract

Background: Soluble fibre has been proposed to suppress appetite-related perceptions and it could thus contribute favourably to the regulation of energy intake and the increasing obesity problem.

Objective: To investigate the effect of an oat ingredient rich in $\beta$-glucan on perceived satiety at different dietary fibre (DF) concentrations, energy levels and viscosity levels.

Design: A total of 29 healthy volunteers, age 19-39, mean BMI $23.2 \mathrm{~kg} / \mathrm{m}^{2}$ participated in this study. Measurement of subjective perceptions (satiety, fullness, hunger, desire to eat something/the sample food and thirst) was performed during a 180-min period after ingestion of the sample. There were altogether six samples: two beverages without fibre at energy levels 700 and $1,400 \mathrm{~kJ}$; two beverages containing 5 or $10 \mathrm{~g}$ oat $\mathrm{DF}$ (2.5 and $5 \mathrm{~g}$ oat $\beta$-glucan, respectively) at energy level $700 \mathrm{~kJ}$, one beverage containing $10 \mathrm{~g}$ oat DF/1,400 $\mathrm{kJ}$ and one beverage containing $10 \mathrm{~g}$ enzymatically treated oat DF with low viscosity at energy level $700 \mathrm{~kJ}$. Each beverage portion weighted $300 \mathrm{~g}$. The order of the samples was randomised for each subject and evaluated during six separate days. The results are reported in three sets of samples: 'fibre', 'energy' and 'viscosity'.

Results: In the fibre set, the beverages containing 5 or $10 \mathrm{~g}$ of fibre had a larger area under curve (AUC) for perceived satiety and smaller AUC for hunger compared to the beverage without fibre, but no significant dose-response relationship was detected. Increasing the energy content from 700 to $1,400 \mathrm{~kJ}$ in the energy set did not affect the satiety-related perceptions. In the viscosity set, the beverage with low-viscosity $\beta$-glucan increased satiety-related perceptions from no fibre containing beverage, but less compared to the beverage with the same amount of fibre and higher viscosity.

Conclusions: Addition of an oat ingredient rich in $\beta$-glucan and high viscosity of beverages enhance post-meal satiety induced by beverages. The effect was, however, not related to the amount of ingested fibre or energy.

Keywords: appetite; hunger; dietary fibre; energy density

Received: 25 June 2009; Revised: 9 February 20I0; Accepted: 17 March 2010; Published: I4 April 2010

$\mathrm{C}$ omposition of food affects its ability to suppress the appetite and boost the satiety after meals (1). Especially, convincing evidence has been presented about the effect of dietary fibre (DF) on appetite and weight management. The great amount of DF in the diet has been linked to the reduction of energy intake and body weight (2) as well as increased satiety (3). This makes it a potential food component favourably affecting weight management and thereby an effective dietary mean for combating the current obesity epidemic.

DF is a nutritional concept and covers a group of substances with different chemical and physical properties (4). The physiological effect of different DF thus highly varies depending on their chemical and physical properties. Oat $\beta$-glucan, a water-soluble viscous polysaccharide, has been linked with many health benefits, such as reduced cholesterol levels and balanced blood glucose 
and insulin levels (5). In addition, the viscosity-forming capacity of water-soluble fibres, such as guar gum and oat $\beta$-glucan, has been suggested to be crucial for their effect on satiety-related attributes (3).

Burton-Freeman (6) and Howarth et al. (2) discuss several possible mechanisms behind the influence of soluble viscous fibres on food intake regulation: the slower gastric emptying time because of increased viscosity of the chyme in the gut as well as longer small intestine passage time and the absorption rate of nutrients, both of which are believed to increase satiety by enhancing satiety mediating signals to the central nervous system. One suggested direct effect of viscous DF on energy intake is the decreased absorption of macronutrients because of the physical barrier formed by DF (2, 6). Viscosity has indeed been shown to inversely affect hunger when subjects were tested with beverages varying in viscosity, which was modified with a very small amount of microcrystalline cellulose (7). In our previous study with three different DFs, the viscosity of soluble fibres, guar gum and oat $\beta$-glucan had a role in their ability to increase satiety (8).

The energy content of food affects its satiating capacity (9). Then again, a diet high in energy may mask the effect of other components, such as DF, on satiety (10). Contrary to Kirkmeyer and Mattes (9), Drewnowski (11) stated that equal-volume preloads with varying energy density have shown contradictory results on hunger and satiety ratings, and that the effect also depends on the time interval between the preload and measurements of appetite-related perceptions or a test meal.

The aim of this study was to investigate the effect of an oat ingredient rich in $\beta$-glucan on perceived satiety by varying the amount of fibre itself, the energy level and the viscosity formed by the fibre in a beverage base. Six beverage samples were designed to create three sets of samples in order to isolate and compare the effects of amounts of fibre, energy levels and viscosity on perceived satiety.

\section{Materials and methods}

\section{Subjects}

A total of 29 healthy volunteers (11 men and 18 women) without dietary restrictions participated in this study. Participants were recruited from the Helsinki University of Technology by email, advertising on bulletin board or contacting personally. The mean age of the subjects was 23.5 years (range 19-39 years) and their mean BMI of $23.2 \mathrm{~kg} / \mathrm{m}^{2}$ (range 18.9-29.7 kg/m ${ }^{2}$ ). Eight of the subjects had a BMI of $25-30 \mathrm{~kg} / \mathrm{m}^{2}$. The participants gave written informed consent to participating in the study.

At the beginning of the study the subjects filled in the Three Factor Eating Questionnaire (TFEQ) (12) and a food frequency questionnaire to briefly assess their eating behaviour and food habits. Based on the TFEQ, the subjects' mean 'cognitive restraint' score was 3.0 (SEM 0.3), 'uncontrolled eating' score 3.0 (SEM 0.4) and 'hunger' score 4.4 (SEM 0.4). Based on the food frequency questionnaire, $93 \%$ of the respondents used white wheat bread and $90 \%$ used fruit or berry-based beverages at least occasionally.

\section{Samples}

The oat ingredient used was a product of Valioravinto PLC, Finland, and contained 34\% DF (of which 50\% $\beta$ glucan) as well as $22 \%$ protein, $18 \%$ carbohydrates and $11 \%$ fat. The test products were beverages with three different levels of added oat fibre ingredient to give a DF content of 0,5 and $10 \mathrm{~g}$, and two different energy levels, 700 and $1,400 \mathrm{~kJ}$ (Table 1). In addition, the viscosity of one fibre-enriched test product was reduced enzymatically. The composition of the samples and ingredients used are described in Table 1. Each beverage portion weighted $300 \mathrm{~g}$ and the energy content was either 700 or $1,400 \mathrm{~kJ}(\sim 167$ or $335 \mathrm{kcal} ; 1 \mathrm{kcal}=4.186 \mathrm{~kJ})$. White wheat bread $(700 \mathrm{~kJ}, 61 \mathrm{~g}$, sliced) was used as an external reference sample. The beverage samples were presented in random order for each subject. At each study visit, a glass $(200 \mathrm{ml})$ of water was served with the samples.

The beverage base of all samples except the one with reduced viscosity was prepared on the previous day and the fibre was mixed into the beverage base with a whisk directly before serving to the subject. As the fibre was mixed into the beverage base directly before consumption, part of the viscosity of the sample was formed in the digestive tract.

The beverage with reduced viscosity was prepared on the previous day by mixing the $\beta$-glucanase enzyme $(0.2 \mathrm{~g}$ Veron HF, Röhm) with the oat DF preparation. The fibre and enzyme mixture was then added to the beverage base and heated in an incubator at $40^{\circ} \mathrm{C}$ for $30 \mathrm{~min}$, stirring occasionally, for making low-viscosity small molecular weight $\beta$-glucan. To inactivate the enzymes, the mixture was removed from the incubator and put in a microwave oven for min at 800 Watts, again stirring occasionally. The sample was then cooled and served on the following day to the subjects. The enzyme treatment did not affect $\beta$-glucan content of the beverages as measured with the Megazyme-method (13).

The six samples formed three sets of comparisons so that the effect of fibre in the 'fibre set' was studied by comparing samples containing 0,5 or $10 \mathrm{~g}$ of fibre at the energy level of $700 \mathrm{~kJ}$ (samples $0 \mathrm{~F} / 700,5 \mathrm{~F} / 700$ and $10 \mathrm{~F} /$ $700 \mathrm{~kJ}$ ); the effect of energy in the 'energy set' was studied by comparing samples containing 700 or $1,400 \mathrm{~kJ}$ energy both at fibre levels 0 and $10 \mathrm{~g}$ (samples $0 \mathrm{~F} / 700$ and $0 \mathrm{~F} /$ $1,400 \mathrm{~kJ} ; 10 \mathrm{~F} / 700$ and $10 \mathrm{~F} / 1400 \mathrm{~kJ}$ ); in the 'viscosity set' the effect of viscosity was studied by comparing the 


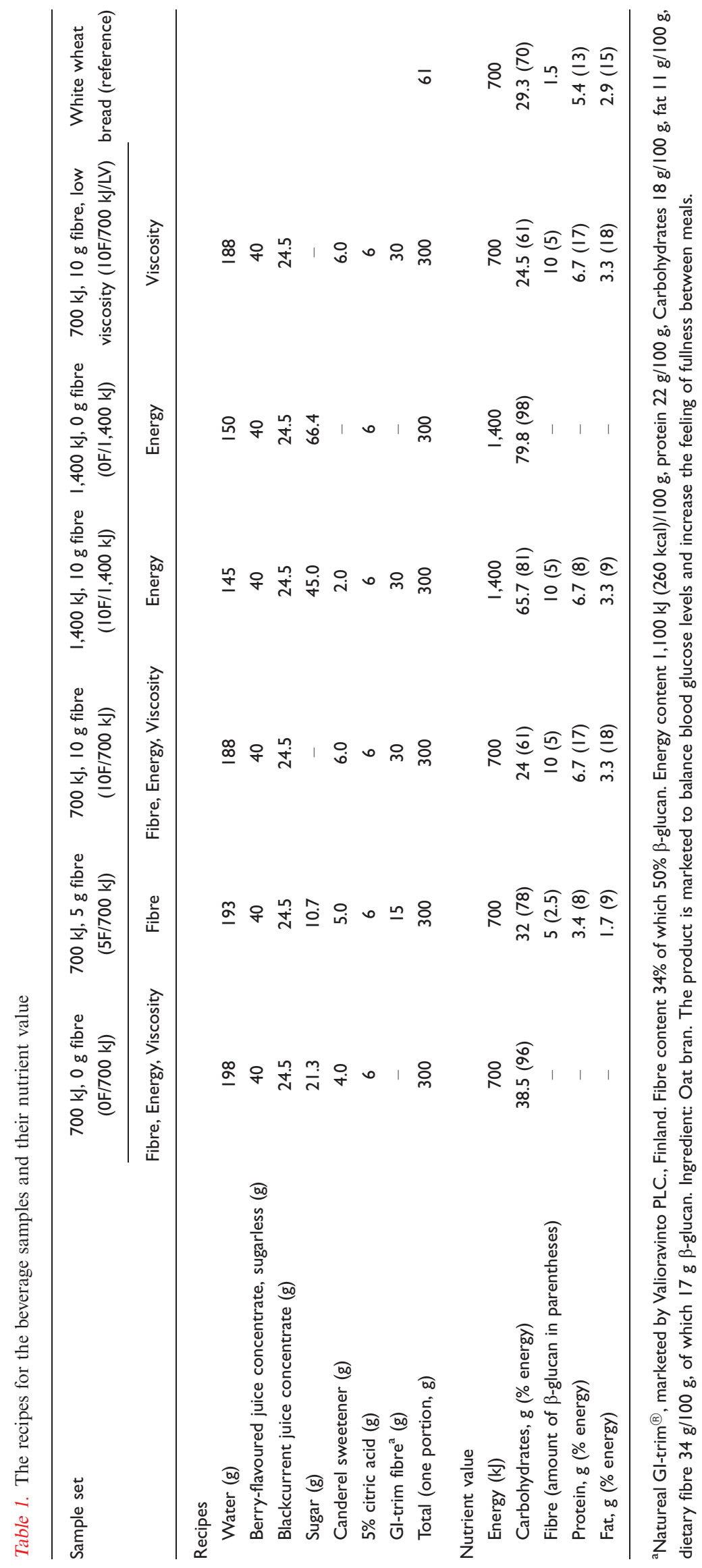


samples containing 0 and $10 \mathrm{~g}$ of fibre with normal or reduced viscosity (samples $0 \mathrm{~F} / 700,10 \mathrm{~F} / 700$ and 10F/700 $\mathrm{kJ} / \mathrm{LV}$ - low viscosity).

\section{Procedure and methods}

Before the actual study the subjects were familiarised with the procedure and trained to use the rating scales with a beverage containing $2.5 \mathrm{~g}$ of oat DF. All eight 3-hour sessions (one practice session, six sessions testing the beverage samples and one session with white wheat bread) were conducted in the morning, after a minimum of 8 hours fast. There was at least one day between the sessions.

The subjects rated their satiety-related perceptions before ingesting the sample and after 20, 40, 60, 90, 120,150 and $180 \mathrm{~min}$ from the beginning of ingestion. The time used for consuming the beverage samples was monitored and the mean time varied between 1 min $54 \mathrm{~s}$ and $3 \mathrm{~min} 28 \mathrm{~s}$ depending on the sample. There were differences between beverages regarding the mean time used for consuming the beverage $[F(5,120)=6.04$; $p<0.001]$, the shortest time being $1 \mathrm{~min} 54 \mathrm{~s}$ for $0 \mathrm{~F} / 700$ $\mathrm{kJ}$ and longest time for samples $10 \mathrm{~F} / 1,400 \mathrm{~kJ}(3 \min 20 \mathrm{~s})$ and $10 \mathrm{~F} / 700 \mathrm{~kJ}$ (3 $\min 38 \mathrm{~s}$ ).

Constant rate measurement of viscosity was performed with StressTech rheometer (CC 25 CCE, Reologica Instruments $\mathrm{AB}$, Sweden) at shear rate $50 \mathrm{~s}^{-1}$ at $+20^{\circ} \mathrm{C}$ for the viscosity set samples $(0 \mathrm{~F} / 700 \mathrm{~kJ}, 10 \mathrm{~F} / 700$ $\mathrm{kJ}$ and $10 \mathrm{~F} / 700 \mathrm{~kJ} / \mathrm{LV}$ ). The samples were prepared in the same way as for the satiety tests. To make sure that the $\beta$-glucanase treatment was successful, the viscosity of the enzymatically treated sample and native sample was measured. The instrumentally measured viscosity of sample $10 \mathrm{~F} / 700 \mathrm{~kJ}$ was clearly higher, 661 $\mathrm{mPas}$ (milli-Pascal-seconds) than the respective sample after $\beta$-glucanase treatment $(10 \mathrm{~F} / 700 \mathrm{~kJ} / \mathrm{LV}), 31.6 \mathrm{mPas}$. The viscosity of the reference beverage without fibre was $1.5 \mathrm{mPas}$. The viscosity of the enzyme-treated beverage remained low after $15 \mathrm{~min}$ following the preparation of the sample. The viscosity of the respective untreated beverage increased rapidly to $1,520 \mathrm{mPa}$ s after $15 \mathrm{~min}$ following the preparation of the beverage and stirring.

\section{Satiety ratings}

The satiety-related sensations were evaluated using a 10unit scale $(0=$ not at all, $10=$ extremely $)$ before the intake of the samples. Immediately after intake and during the following $180 \mathrm{~min}$, satiety was rated as a change from the starting value with a $-10-0-+10$ scale $(-10=$ a lot less than at the beginning, $0=$ as much as in that beginning, $+10=\mathrm{a}$ lot more than in the beginning) where 0 represents the baseline value. For example, rating hunger as ' -3 ' would indicate that the subject felt less hungry than at the beginning of that session.
A total of five satiety/hunger-related attributes were rated. Two of the scales measured hunger/desire to eat something, two of the scales measured satiety/fullness. One scale measured sensory-specific satiety (desire to eat the sample food). Thirstiness was measured as a control question. The factor analysis (Maximum likelihood with Varimax rotation) revealed that satiety and hungerrelated attributes loaded on different factors, although being highly negatively correlated (data not presented). Therefore, the results are presented by two attributes representing the highest loadings in the two factors: perceived satiety and hunger ( 0.95 and 0.83 , respectively). In addition, thirstiness is reported. The data were collected by using a computerised data-collecting system (CSA, Computerized Sensory Analysis System, Compusense Inc., Guelph, Canada, Compusense 5, version 4.6.702 SP3).

\section{Data analysis}

Results were analysed as graphical curves of changes in satiety-related feelings from the baseline levels as a function of time and the area under curve (AUC, $\mathrm{cm} \times$ min) was calculated. The possible area under/over the starting level was subtracted. We marked the AUC below baseline level with '-' (hunger, desire to eat the sample food/something) and the AUC above baseline with ' + ' (satiety, fullness). All curves followed the same pattern with the lowest or highest ratings $20 \mathrm{~min}$ after eating the sample and then scores increased or decreased, respectively, during the 3-hour follow-up time.

Repeated Measures General Linear Model (GLM repeated) was used in the statistical analysis of the satiety evaluations. If differences in AUCs between products were found, further analysis was conducted with the pairedsamples $t$-test. Correlation analyses were performed using Pearson's correlation coefficient (two-tailed). SPSS software (version 14.0, SPSS Inc. Chicago, IL, USA) was used for all of the statistical analyses.

\section{Results}

\section{Effect of amount of fibre}

Responses to the three samples containing either 0,5 or $10 \mathrm{~g}$ of DF at energy level $700 \mathrm{~kJ}$ (samples $0 \mathrm{~F} / 700,5 \mathrm{~F} / 700$ and $10 \mathrm{~F} / 700 \mathrm{~kJ}$ ) were compared in this set. Main effects of product and time were found regarding perceived satiety and hunger, and overall product-time interaction for satiety (Figs. 1 and 2). There were differences between the samples in the total AUC for perceived satiety $[F(2$, $56)=12.78 ; p<0.001]$ and hunger $[F(2,56)=12.23$; $p<0.001$ ] (Table 2). The added DF, either $5 \mathrm{~g}(t$-test value $-3.2, p=0.003)$ or $10 \mathrm{~g}$ ( $t$-test value -5.0 , $p<0.001)$, increased the feeling of satiety and decreased hunger ( $5 \mathrm{~g}$; $t$-test value $3.7, p=0.001,10 \mathrm{~g}$; $t$-test value 4.2, $p<0.001$ ) compared to the $0 \mathrm{~F} / 700 \mathrm{~kJ}$ beverage, but 


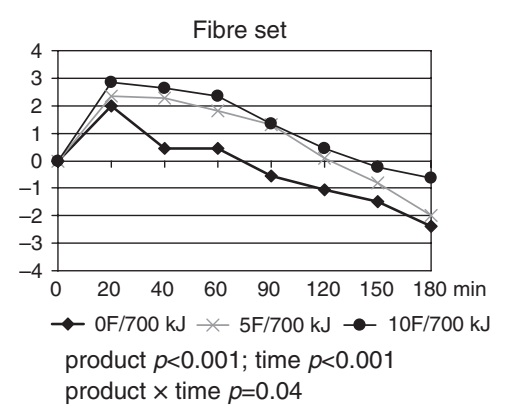

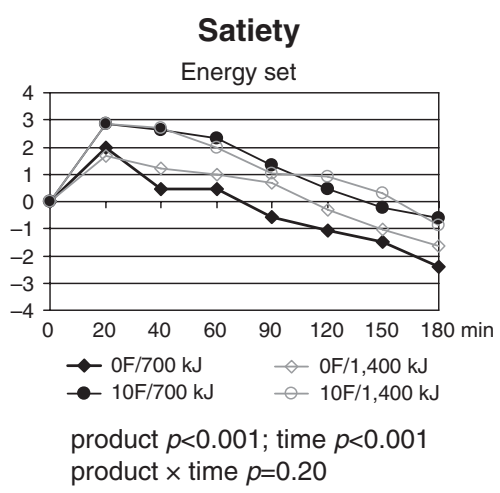

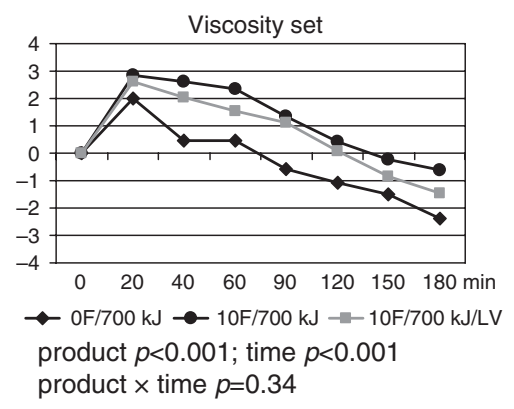

product $\times$ time $p=0.34$

Fig. 1. Changes in the mean ratings for perceived satiety after consumption of beverage samples (180-min follow-up time) in the fibre, energy and viscosity set of samples.

there was no significant difference between the lower $(5 \mathrm{~g})$ and higher (10 g) DF levels.

\section{Effect of energy at two different dietary fibre (DF) levels}

Responses to the four samples containing either $0 \mathrm{~g}$ DF and 700 or $1,400 \mathrm{~kJ}$ of energy or $10 \mathrm{~g} \mathrm{DF}$ and 700 or $1,400 \mathrm{~kJ}$ of energy (samples $0 \mathrm{~F} / 700$ and $0 \mathrm{~F} / 1,400 \mathrm{~kJ} ; 10 \mathrm{~F} /$ 700 and $10 \mathrm{~F} / 1,400 \mathrm{~kJ}$ ) were compared in this set. Main effects of product and time were found regarding perceived satiety and hunger, but no overall producttime interactions were found (Figs. 1 and 2). Increase of energy content, from 700 to $1,400 \mathrm{~kJ}$ by using sucrose did not result in significantly higher satiety AUC or decreased hunger AUC (Table 2). At both levels of energy, DF had the same increasing effect on satiety and decreasing effect on hunger ratings.

\section{The effect of viscosity of beverage on satiety and hunger}

Responses to the three samples containing either 0 or $10 \mathrm{~g}$ of DF at energy level $700 \mathrm{~kJ}$, with normal or reduced viscosity in the DF-containing beverages (samples $0 \mathrm{~F} /$ $700,10 \mathrm{~F} / 700$ and $10 \mathrm{~F} / 700 \mathrm{~kJ} / \mathrm{LV}$ ) were compared in this set. Main effects of product and time were found regarding perceived satiety and hunger, but no overall product-time interactions were found (Figs. 1 and 2). There were differences between the samples in the total AUC for perceived satiety $[F(2,56)=15.2 ; p<0.001]$ and hunger $[F(2,56)=10.28 ; p<0.001]$ (Table 2). The enzymatically treated $10 \mathrm{~F} / 700 \mathrm{~kJ} / \mathrm{LV}$ beverage produced significantly lower ratings of satiety than the $10 \mathrm{~F} / 700 \mathrm{~kJ}$ beverage ( $t$-test value $2.1, p=0.048$ ). The $0 \mathrm{~F} / 700 \mathrm{~kJ}$ beverage differed significantly from both of the beverages containing $10 \mathrm{-g}$ fibre either with low ( $t$-test value -3.5 , $p=0.001)$ or high viscosity $(t$-test value $-5.0, p<0.001)$ regarding the AUC for satiety. Both of the DF-containing beverages had larger AUCs for hunger (low viscosity; $t$ test value $3.0, p=0.005$ ) (high viscosity; $t$-test value 4.3 , $p<0.001)$ compared to the beverage without DF, thus suppressing hunger more. The $10 \mathrm{~F} / 700 \mathrm{~kJ} / \mathrm{LV}$ beverage did not differ from the $10 \mathrm{~F} / 700 \mathrm{~kJ}$ beverage regarding hunger.

\section{Perceived thirst}

Regardless of the comparisons there were not statistical differences in the AUC for thirstiness between the samples. The AUCs ranged from -352 to $-429 \mathrm{~cm} \times \min$ and were similar for all six beverage samples.
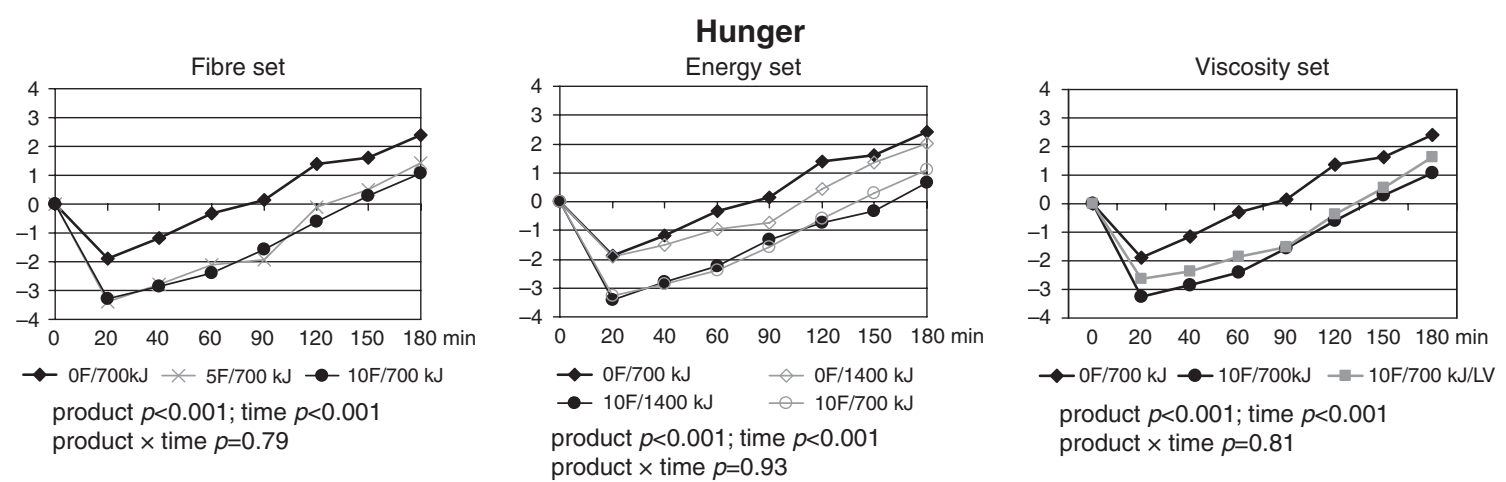

Fig. 2. Changes in the mean ratings for perceived hunger after consumption of beverage samples (180-min follow-up time) in the fibre, energy and viscosity set of samples. 


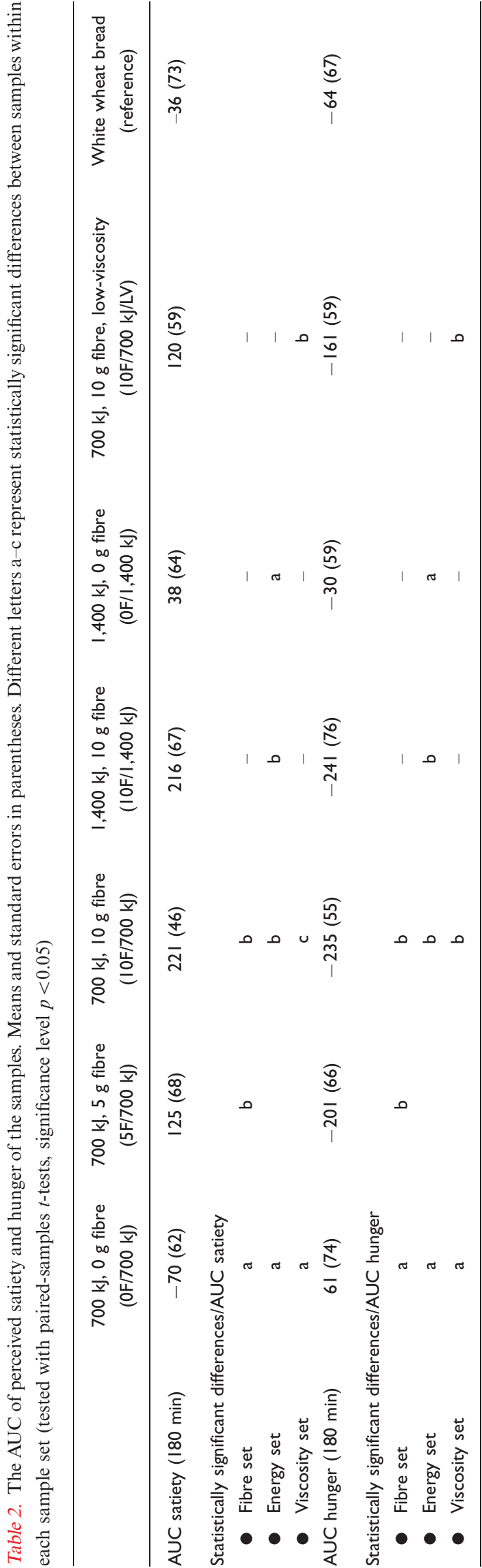

\section{White wheat bread as a reference sample compared to beverage samples}

Regarding the beverage samples containing fibre (samples 5F/700, 10F/700, 10F/1,400 and 10F/700 kJ/LV), their AUCs of satiety were higher and AUCs hunger were lower in contrast to the white wheat bread sample. The AUC for hunger and satiety of the two beverage samples without fibre (samples $0 \mathrm{~F} / 700$ and $0 \mathrm{~F} / 1,400 \mathrm{~kJ}$ ) were close to AUCs of the white wheat bread sample.

\section{Discussion}

The aim of this study was to investigate the effect of an oat ingredient rich in $\beta$-glucan on perceived satiety by isolating and comparing the effects of amount of DF, energy level and viscosity on perceived satiety. Our results demonstrate that beverages containing oat fibre is rich in $\beta$-glucan increase post-meal satiety and the effect was related both to DF and viscosity of the beverages, but not to energy content or the amount of DF.

\section{Effect of fibre}

DF content affected ratings of perceived satiety but showed no dose-response relationship, when amount of DF was doubled from 5 to $10 \mathrm{~g}$ in the $300 \mathrm{~g}$ beverage sample. The beverage containing $5 \mathrm{~g}$ of $\mathrm{DF}$ produced significantly higher ratings of satiety than the beverage without fibre. However, when the dose was raised to $10 \mathrm{~g}$ of DF, although ratings were systematically higher, no significant difference was observed between the two DF levels (5 and $10 \mathrm{~g}$ ). It seems that for achieving increased perceived satiety, the addition of $5 \mathrm{~g}$ oat fibre $(2.5 \mathrm{~g}$ $\beta$-glucan) can already be a sufficient amount. This result is promising from the technological point of view. As oat $\beta$-glucan increases the viscosity of the beverage, large amounts are challenging both technologically and from the consumer acceptance viewpoint.

Also our previous study with beverages containing oat $\beta$-glucan, guar gum or wheat bran showed the satiating capacity of beverage containing $10 \mathrm{~g}$ oat DF, of which $5 \mathrm{~g}$ was $\beta$-glucan (8), although not as clearly as in the current study. Few other studies have reported the use of $\beta$-glucan, either from oat or barley, and they have also used other carrier foods than beverage. In a study by Kim et al. (14), a smaller ( $2 \mathrm{~g}$ ) dose of barley $\beta$-glucan, served as cooked cereal with yoghurt, did not affect satiety ratings compared to isocaloric glucose load. Howarth et al. (15) compared a mixture of pectin and $\beta$-glucan with methylcellulose in a gelatine-like pudding for three weeks at a daily dose of $27 \mathrm{~g}$ (2:1 ratio of pectin to $\beta$-glucan), showing that methylcellulose was slightly more satiating than the pectin/ $\beta$-glucan mixture. Muesli containing 4-g oat $\beta$-glucan did not differ from an isocaloric portion of cornflakes regarding the satiety effects (16).

All of these other studies using $\beta$-glucan had solid or semi-solid foods as carrier foods. Because solid foods 
have been found to increase satiety and decrease hunger more effectively than liquid foods (9), it is possible that the larger satiating effect of solid food in itself drowns the weaker satiating potential of fibre. In beverages, however, fibre could be used to boost their satiating capacity closer to the level of solid or semi-solid foods, or even above it, which was the case in our study when compared to white wheat bread. This could offer an interesting possibility for the beverage industry to produce functional beverages with improved effect of liquid calories on satiety.

\section{Effect of energy}

In this study the energy level of the beverages did not seem to affect satiety. Both the beverages containing 0 or $10 \mathrm{~g}$ fibre and 700 or $1,400 \mathrm{~kJ}$ had similar effects on satietyrelated perceptions. The addition of fibre increased feelings of satiety and decreased hunger independently, regardless of energy level.

In other studies the effect of energy content on satietyrelated perceptions has been somewhat inconsistent. Differences between the AUCs for 'appetite for meal' after 1,260 and 2,510 $\mathrm{kJ}$ preloads (rating time 2 hours) were not significant when the weight of the preloads was constant, being either 250,500 or $750 \mathrm{~g}$ (17). Gray et al. (18) demonstrated that subjective appetite after soup preloads was reduced when the volume of the preload increased but was not affected by energy content. In their study the energy contents compared were 629 and 1,886 $\mathrm{kJ}$ at volume level $450 \mathrm{ml}$, which are relatively close to those used in our study. Contrary to these findings and our finding, Kirkmeyer and Mattes (9) proposed that energy content of the food would be the main factor influencing hunger.

Our results showing the increasing effect of fibre on satiety-related perceptions also on a lower energy level propose that the addition of fibre could be useful in increasing satiety at a moderate energy levels. Previously it has been found that guar gum supplementation $(20 \mathrm{~g} / \mathrm{d})$ reduced hunger and increased satiety at 4 MJ dietary energy level, but not at $6 \mathrm{MJ}$ dietary energy level (10). The lower energy level used in the study $(700 \mathrm{~kJ} / 300 \mathrm{~g})$ is comparable to many juices and milk-based drinks.

\section{Effect of viscosity}

In the earlier studies the viscosity of beverages has been shown to have a decreasing effect on hunger $(7,19,20)$. In line with these results, in our study the most viscous beverage increased the perceived satiety significantly more than the beverage containing the same amount of fibre (10 g), but with enzymatically lowered viscosity. The AUC for decreased hunger was also larger for the untreated, high-viscosity beverage but it did not differ statistically significant from the treated low-viscosity beverage. Both of the fibre-containing beverages increased satiety and decreased hunger more effectively compared to the beverage without fibre. The instrumentally measured viscosities of the beverage without fibre and the enzymatically treated beverage with $10 \mathrm{~g}$ fibre were very close to each other, 1.5 and $31.6 \mathrm{mPa} \mathrm{s}$, respectively. Thus, oat $\beta$-glucan may have the ability to increase feelings related to satiety even though its viscosity has been lowered. In fact, in another study reported by our group (21), the beverage with enzymatically lowered viscosity produced greater satiety than the beverage with the same amount of fibre $(10 \mathrm{~g})$ with its natural viscosity. The development of satiety and the effect of different food characteristics on it is thus a very complex issue influenced also by many yet unknown factors. However, what comes to the physical form of a food, the results are rather consistent in finding that calories in liquid form are not sensed as well as those in solid form (22-24).

\section{Limitations of the study}

The satiety-related sensations were evaluated using a -10 to +10 scale after the intake of the sample. This modified scale proved to be efficient in identifying differences between samples. When satiety is measured as a change from the baseline, evaluation and thus the starting value is anchored, and the scale can be used more widely. With the more common 10-unit scale if the starting value is high, for example, the use of the scale is far more restricted and actual changes in satiety levels are harder to obtain.

It could be argued that this modified scale steers the answers of the respondents; when compared to the starting level, it can be assumed that food reduces sensations of hunger and increases satiety. However, it can be assumed that this error would apply to all of the samples and should not affect the differences between the samples.

Regarding the differences between the mean consumption times of the samples, it is possible that they have had an effect on the ratings, especially at 20-min time point. However, the possible effect on the total AUC/180 min is very likely small.

The oat fibre preparation used was enriched with DF (34\%) of which $50 \%$ was $\beta$-glucan, but it also contained $22 \%$ protein. It was a commercial DF preparation designed to deliver high viscosity. It can thus not be claimed that the effects detected were solely caused by $\beta$ glucan although it is highly probable that it was the most influential component in the ingredient. When $\beta$-glucan was depolymerised and thus viscosity reduced, the satiety scores were reduced.

\section{Conclusions}

An oat ingredient rich in $\beta$-glucan, added to beverages with moderate energy content increased satiety-related and decreased hunger-related perceptions compared to a 
beverage without DF during 3-hour follow-up time after ingestion. Both the DF content and viscosity of the beverages had independent effects on satiety-related perceptions, whereas increasing energy content did not affect satiety. The effect of the amount of DF, however, did not have a direct/linear dose-response relationship. DF could be used in beverages to boost their satietyenhancing capacity. However, the relationship between increased short-term satiety and actual food intake, and weight management needs to be studied in long-term studies.

\section{Conflict of interest and funding}

The authors would like to acknowledge TEKES (Finnish Funding Agency for Technology and Innovation) and Atria Plc, Fazer Bakeries Ltd, Arla Ingman Oy Ab, Raisio Plc, Oy Sinebrychoff Ab and Valio Ltd for partly funding this research.

\section{References}

1. Rolls BJ, Hetherington M, Burley VJ. The specificity of satiety: the influence of foods of different macronutrient content on the development of satiety. Physiol Behav 1988; 43: 145-53.

2. Howarth NC, Saltzman E, Roberts S. Dietary fiber and weight regulation. Nutr Rev 2001; 59: 129-39.

3. Slavin J, Green H. Dietary fibre and satiety. Nutr Bull 2007; 32: $32-42$.

4. Commission Directive 2008/100/EC of 28 October 2008 amending Council Directive 90/496/EEC on nutrition labelling for foodstuffs as regards recommended daily allowances, energy conversion factors and definitions. Official Journal of the European Union L285/9, 29.10.2008; 2008. http://eur-lex.eur opa.eu/LexUriServ/LexUriServ.do?uri=OJ:L:2008:285:0009:0012: EN:PDF [cited 8 February 2010].

5. Wood PJ. Cereal $\beta$-glucans in diet and health. J Cereal Sci 2007; 46: $230-8$.

6. Burton-Freeman B. Dietary fiber and energy regulation. J Nutr 2000; 130: S272-5.

7. Mattes RD, Rothacker D. Beverage viscosity is inversely related to postprandial hunger in humans. Physiol Behav 2001; 74: $551-7$.

8. Lyly M, Liukkonen K-H, Salmenkallio-Marttila M, Karhunen L, Poutanen K, Lähteenmäki L. Fibre in beverages can enhance perceived satiety. Eur J Nutr 2009; 48: 251-8.

9. Kirkmeyer SV, Mattes RD. Effects of food attributes on hunger and food intake. Int J Obes 2000; 24: 1167-75.

10. Pasman WJ, Saris WHM, Wauters MAJ, Westerterp-Plantenga MS. Effect of one week of fibre supplementation on hunger and satiety ratings and energy intake. Appetite 1997; 29: 77-87.

11. Drewnowski A. The role of energy density. Lipids 2003; 38: 109-15.
12. Stunkard AJ, Messick S. The three-factor eating questionnaire to measure dietary restraint, disinhibition and hunger. J Psychosom Res 1985; 29: 71-83.

13. McCleary B, Codd R. Measurement of (1-3),(1-4)- $\beta$-D-glucan in barley andoats: a streamlined enzymic procedure. J Sci Food Agric 1991; 55: 303-12.

14. Kim H, Behall KM, Vinyard B, Conway JM. Short-term satiety and glycemic response after consumption of whole grains with various amounts of $\beta$-glucan. Cereal Foods World 2006; 51: 29-33.

15. Howarth NC, Saltzman E, McCrory MA, Greenberg AS, Dwyer J, Ausman L, et al. Fermentable and non-fermentable fiber supplements did not alter hunger, satiety or body weight in a pilot study of men and women consuming self-selected diets. J Nutr 2003; 133: 3141-4

16. Hlebowicz J, Darwiche G, Björgell O, Almér L-O. Effect of muesli with $4 \mathrm{~g}$ oat $\beta$-glucan on postprandial blood glucose, gastric emptying and satiety in healthy subjects: a randomized crossover trial. J Am Coll Nutr 2008; 27: 470-5.

17. De Graaf C, Hulshof T. Effects of weight and energy content of preloads on subsequent appetite and food intake. Appetite 1996; 26: $139-51$.

18. Gray RW, French SJ, Robinson TM, Yeomans MR. Dissociation of the effects of preload volume and energy content on subjective appetite and food intake. Physiol Behav 2002; 76: $57-64$.

19. Marciani L, Gowland PA, Spiller RC, Manoj P, Moore RJ, Young P, et al. Gastric response to increased meal viscosity assessed by echo-planar magnetic resonance imaging in humans. J Nutr 2000; 130: 122-7.

20. Marciani L, Gowland PA, Spiller RC, Manoj P, Moore RJ, Young P, et al. Effect of meal viscosity and nutrients on satiety, intragastric dilution, and emptying assessed by MRI. Am J Physiol Gastrointest Liver Physiol 2001; 280: 1227-33.

21. Juvonen KR, Purhonen A-K, Salmenkallio-Marttila M, Lähteenmäki L, Laaksonen DE, Herzig K-H, et al. Viscosity of oat bran-enriched beverages influences gastrointestinal hormonal responses in healthy humans. J Nutr 2009; 139: 461-6.

22. Zijlstra N, Mars M, de Wijk RA, Westerterp-Plantega MS, de Graaf C. The effect of viscosity on ad libitum food intake. Int J Obes 2008; 32: 676-83.

23. Zijlstra N, Mars M, de Wijk RA, Westerterp-Plantega MS, Juul Holst J, de Graaf C. Effect of viscosity on appetite and gastrointestinal hormones. Physiol Behav 2009; 97: 68-75.

24. Mattes RD. Dietary compensation by humans for supplemental energy provided as ethanol or carbohydrate in fluids. Physiol Behav 1996; 59: 179-87.

\footnotetext{
*Marika Lyly

Finnish Food Safety Authority Evira

Mustialankatu 3, Fl-00790 Helsinki, Finland

Tel: +358400105787

Fax: + 358207725025

Email: marika.lyly@evira.fi
} 